\title{
JOURNAL OF BORNEO-KALIMANTAN(JBK)
}

\section{Satu Sorotan Literatur Tentang Penglibatan Sosial Belia Berstatus Sosio- Ekonomi Rendah}

\author{
Dolly Paul Carlo ${ }^{1 *}$ dan Kamsiah Bt. Ali ${ }^{2}$ \\ 1,2, Faculty of Social Science, Universiti Malaysia Sarawak, 94300 Kota Samarahan, Sarawak, Malaysia \\ *Corresponding author \\ Email address: pcdolly@unimas.my
}

\begin{abstract}
ABSTRAK
Golongan belia merupakan aset penting sesebuah negara. Oleh yang demikian fokus pembangunan belia perlu diberi keutamaan bagi memastikan kelangsungan kemajuan sesebuah negara. Penyertaan sosial dalam masyarakat dipengaruhi oleh status sosio-ekonomi (SES) individu. Status sosioekonomi merupakan gabungan pengukuran berdasarkan pendapatan, pendidikan dan pekerjaan individu dan keluarga. Sorotan kajian lepas mendapati pendapatan dan pendidikan rendah individu atau keluarga merupakan petunjuk kepada pelbagai masalah sosial, kesihatan fizikal dan mental. Status kesihatan merupakan salah satu faktor penting dalam sumber daya manusia, yang merupakan modal penting dalam pembangunan suatu bangsa. Dalam masyarakat yang status sosio-ekonominya rendah, para belia sangat terdedah kepada pelbagai risiko kesihatan dan masalah sosial, contohnya keciciran pendidikan, pengangguran, penglibatan dalam aktiviti devian dan jenayah, penyalahgunaan dadah dan masalah kesihatan fizikal dan mental. Kajian berbentuk penerokaan yang akan dilakukan ini bertujuan mengkaji pengaruh status sosio-ekonomi rendah dan penyertaan sosial belia di kawasan Sadong Jaya dan Samarahan. Kajian yang dilakukan memfokuskan penyertaan belia dalam pekerjaan, pendidikan dan masalah sosial. Namun dalam kertas kerja ini fokus perbincangan adalah berkaitan dengan sorotan lepas yang berkisar dengan status sosio-ekonomi dan penglibatan sosial dalam kalangan belia.
\end{abstract}

Youth is the importance asset of a country. The focus of youth development should be given priority in order to sustain development of a country. Social participations in the society are influenced by an individual socio-economic status (SES). SES is a combination of measurement based on individual and family income, and education and occupation. Literature review shows that low income and poor education of individual and family are the indicators to array of social problems, and poor physical and mental health. Health status is one of important factors in human resource which is an important resource of development of any nation. In low SES society, youth is very vulnerable to various social and health risks, for examples, dropping out from educational systems, unemployment, and involvement in criminal and delinquent activities, drug abuse, and poor physical and mental health. This exploratory study aims to study youth in the influence of low SES and their social participations in Sadong Jaya and Samarahan areas. The focus is on their occupation, and education and social problems. However, in this working paper the focus of discussion is only based on literature review which is social participation of low SES youth.

Kata Kunci: Status Sosio-Ekonomi (SES), Golongan Belia, Penglibatan Sosial, Masalah Sosial. 


\section{PENGENALAN}

Golongan belia merupakan aset penting sesebuah negara. Oleh yang demikian fokus pembangunan belia perlu diberikan keutamaan bagi memastikan kelangsungan kemajuan sesebuah negara. Menurut Pertubuhan Bangsa-Bangsa Bersatu, belia ditakrifkan sebagai individu yang berumur dalam kalangan 15 hingga 25 tahun (UNESCO). Sementara Dasar Pembangunan Belia Negara mentakrifkan belia sebagai mereka yang berumur antara 15 hingga 40 tahun (Dasar Pembangunan Belia Negara, 1997). Walau pun takrifan umur belia di Malaysia merujuk kepada individu berumur antara 15 hingga 40 tahun namun aktiviti dan program pembangunan belia di negara ini lebih memberi fokus kepada belia berumur 18 hingga 25 tahun (Mohd Razali \& Sarjit, 2010; Faizah, 2007; Kementerian Belia Dan Sukan, 1997).

Pembangunan dan penyertaan sosial mereka dipengaruhi oleh status sosio-ekonomi Zmerli (2002). Status sosio-ekonomi (SES) merupakan gabungan pengukuran berdasarkan pendapatan, pendidikan dan pekerjaan individu dan keluarga. Ini ditegaskan oleh Bradley dan Corwyn (2002) yang menyatakan status sosio-ekonomi keluarga biasanya merujuk kepada pendapatan, pendidikan dan pekerjaan ibu bapa. Bila menganalisis status sosio-ekonomi sesebuah keluarga, pendapatan isi rumah, pendidikan dan pekerjaan berpendapatan serta gabungan pendapatan keluarga akan diperiksa, dibanding dengan kedudukan individu itu sendiri. Status sosio-ekonomi biasanya dipecahkan kepada tiga kategori: SES tinggi, SES sederhana dan SES rendah. Sesebuah keluarga atau individu boleh tergolong dalam mana-mana tiga kategori ini. Apabila meletakkan sesebuah keluarga atau individu ke dalam salah satu kategori ini, mana-mana satu atau semua pembolehubah (pendapatan, pendidikan dan pekerjaan) boleh dinilai.

Pendapatan dan pendidikan rendah individu atau keluarga merupakan pertunjuk kepada pelbagai masalah sosial termasuklah kesihatan fizikal dan mental. Keadaan ini mungkin disebabkan oleh keadaan persekitaran tempat kerja yang tidak kondusif dan sihat. Dalam kes tekanan hidup, pendapatan dan pendidikan yang rendah merupakan permulaan kepada permasalahan sosial lain kepada individu. Kajian Rozumah Baharudin, Rumaya Juhari, Asnarul Abu Samah, Tan Jopei, Amna Md. Nor dan Mansor Abu Talib (2005) mengenai 'Predictors of conduct problems among schoolgoing adolescents in West Malaysia' mendapati beberapa faktor individu dan persekitaran berkait secara signifikan dengan penglibatan mereka dalam masalah sosial.

Pendidikan merupakan sesuatu yang dianggap sangat penting dalam isi rumah atau komuniti setempat yang mempunyai status sosio-ekonominya tinggi. Sementara dalam keluarga atau komuniti yang status sosio-ekonominya rendah, keperluan makanan merupakan keutamaan sementara pendidikan menjadi hal yang kedua. Dalam masyarakat yang status sosio-ekonominya rendah, para belia sangat terdedah kepada pelbagai risiko masalah kesihatan dan sosial, contohnya keciciran pendidikan, pengangguran, penglibatan dalam aktiviti devian dan jenayah, penyalahgunaan dadah dan tekanan hidup. Pendek kata, status sosio-ekonomi individu mempengaruhi penyertaan sosial mereka dalam masyarakat (Zmerli, 2002).

\section{Status Sosio-ekonomi dan Penglibatan Sosial Belia}

Berdasarkan sorotan lepas sama ada kajian secara langsung atau tidak langsung terhadap status sosioekonomi dengan penglibatan sosial belia, kebanyakan mendapati penglibatan sosial belia ada hubungkaitnya dengan status sosio-ekonomi. Dalam membincangkan perkara ini fokus kertas kerja ini berkisar terhadap sorotan kajian lepas yang terpilih yang berfokus kepada pendapatan, pendidikan dan pekerjaan dengan pengaruh terhadap penglibatan belia dalam masalah sosial dan implikasi ke atas kesihatan.

\section{Pendapatan Hubungannya dengan Masalah Sosial dan Kesihatan}

Beberapa sorotan kajian lepas mendapati pendapatan yang rendah secara langsung atau tidak langsung mempengaruhi penglibatan sosial belia dalam aspek masalah sosial dan kesihatan. Sorotan kajian lepas ini sama ada di dalam negara mahu pun di luar negara. Beberapa kajian yang dijalankan di 
Malaysia menunjukkan salah satu faktor penglibatan remaja dengan tingkah laku devian adalah disebabkan pendapatan ibu bapa yang rendah (Arieff \& Wardah, 2006). Kajian yang dibuat oleh Noor Adiah (1998) dan Norhayati (1994) juga mendapati masalah sosial ada kaitan dengan pendapatan keluarga. Malahan kemiskinan ibu bapa dapat membatasi galakkan dan dorongan ibu bapa kepada anak-anak mereka untuk bersekolah dan ini akhirnya mengakibatkan anak-anak mereka tercicir dari alam persekolahan (Dolly, 2016). Ini terutamanya dengan pendapatan yang rendah dan pekerjaan yang tidak tetap menyebabkan ibu bapa tidak berkemampuan untuk menampung perbelanjaan persekolahan anak-anak yang ramai. Menurut Psacharopoulos (2007), implikasi seterusnya daripada keciciran dari alam persekolahan mengakibatkan kadar rendah untuk mendapat peluang pekerjaan, pendapatan, mempengaruhi status kesihatan dan ketidakpuasan dalam kehidupan.

Sementara menurut kajian yang dilakukan di negara barat oleh Mannes, Roehlkepartain, dan Benson, (2005) mendapati remaja yang berasal daripada keluarga berpendapatan rendah adalah dua kali ganda lebih cenderung untuk bertingkah laku negatif berbanding dengan remaja lain. Pendapatan keluarga yang rendah menyebabkan belia berisiko terdedah kepada tingkah laku devian seperti ponteng sekolah (Ronka, Kinnunen \& Pulkkinen, 2000). Walau pun kajian dilakukan terhadap belia di Hong Kong oleh Man Oi Ling (2013) mendapati sosio-ekonomi keluarga tiada hubung kaitnya secara langsung dengan masalah tingkah laku devian kalangan belia namun sosio-ekonomi keluarga ada hubungan dengan tingkah laku tersebut melalui perapatan sosial (social bonding). Beliau berpendapat pendidikan ibu bapa yang rendah mempengaruhi ketidak bertanggunjawaban cara keibubapaan (parenting style) terhadap anak-anak dengan itu tingkah laku devian belia dikaitkan dengan cara keibubapaan. Cara keibubapaan inilah yang ada kaitan langsung dengan perapatan sosial. Ini bersamaan dengan apa yang ditegaskan oleh Veenstra, Lindenberg, Oldehinkel, De Winter, dan Ormel (2006), tingkah laku devian ada kaitannya dengan belia berstatus kelas rendah disebabkan perapatan sosial yang kurang dengan ibu bapa.

\section{Pendidikan Hubungannya dengan Masalah Sosial dan Kesihatan}

Menurut Psacharopoulos (2007), pendidikan yang baik membawa cara gaya hidup yang sihat yang menjurus ke arah kesihatan dan kesejahteraan. Pendidikan mempengaruhi kesihatan. Melalui pendidikan boleh memperkasakan individu untuk mempunyai kefahaman yang lebih baik terhadap risiko kesihatan terutamanya berhubung kait dari segi diet permakanan, persekitaran, keadaan pekerjaan, tekanan dan ketagihan serta apa-apa sokongan lain yang membolehkan keupayaan individu tersebut untuk bertanggungjawab terhadap kesihatan kendiri (Brenner, 2009). Status kesihatan merupakan salah satu faktor penting dalam sumber daya manusia, yang merupakan modal penting dalam pembangunan suatu bangsa. Kualiti sumber daya manusia dipengaruhi oleh beberapa faktor, salah satunya adalah tahap pendidikan. Malahan ini ditegaskan oleh Julianty Pradono dan Ning Sulistyowati (2013) yang menyatakan tahap pendidikan ada hubungkaitnya dengan status kesihatan individu. Bila seseorang mempunyai tahap pendidikan yang lebih baik tahap kesedaran dan penjagaan mengenai kesihatan adalah lebih baik. Status kesihatan adalah sebagai salah satu modal dasar dalam pengembangan sumber daya manusia.

\section{Pekerjaan Hubungannya dengan Masalah Sosial dan Kesihatan}

Menurut laporan EACEA, European Commission, (2013) tanpa pekerjaan, ia merupakan satu ancaman kepada kesejahteraan bagi belia. Menurut laporan tersebut lagi, kemiskinan dan pekerjaan secara kontrak yang tidak terjamin dan berpendapatan rendah bermakna belia berdepan dengan pelbagai masalah lain. Ini termasuklah untuk memiliki rumah berkualiti, jaminan kebendaan, pendidikan dan latihan berkualiti, penjagaan kesihatan yang baik, aktiviti rekreasi, serta untuk mendapat kaunseling yang profesional sekiranya berdepan dengan masalah emosi. Kurang peluang untuk mendapat pekerjaan mengakibatkan ketidakselesaan dari aspek psikologi yang membawa kepada perasaan rendah diri dan keyakinan. Keadaan ini seterusnya akan menjejaskan kesihatan diri individu tersebut. Kemiskinan memberi kesan kepada kualiti kehidupan. Dengan tiada pendidikan dan 
pekerjaan, ini membawa kesan kepinggiran jangka panjang belia dalam aspek sosial dan politik yang seterusnya meningkatkan perasaan kebergantungan, tiada kuasa dan berdepan dengan tekanan. Tanpa pekerjaan, pendidikan dan latihan membawa risiko kepada tingkah laku tidak sihat, menyumbang kepada keadaan kesihatan yang teruk dan pengasingan sosial yang lanjut (EACEA, European Commission, 2013).

\section{KESIMPULAN}

Kebiasaannya status sosio-ekonomi merupakan gabungan pengukuran berdasarkan pendapatan, pendidikan dan pekerjaan individu dan keluarga. Bagaimana pengukuran status sosioekonomi golongan belia diambil kira adalah penting. Scutella, Wilkins, dan Horn (2009) menyarankan pengukuran tersebut hendaklah mengambil kira perkara seperti sumber material, penglibatan sosial dan ekonomi, pendidikan dan kesihatan, serta penglibatan dalam komuniti, pendidikan dan ketercapaian kepada perkhidmatan. Sorotan kajian lepas mendapati status sosioekonomi yang rendah sama ada secara langsung atau tidak langsung mempengaruhi penglibatan sosial belia. Pendidikan, Pekerjaan dan pendapatan sebagai ukuran kepada status sosio-ekonomi individu dan keluarga saling berkaitan antara satu sama lain dan ini mempengaruhi serta memberi implikasi kepada penglibatan sosial golongan belia. Pendapatan, pendidikan dan pekerjaan individu dan keluarga saling mempengaruhi pelbagai masalah sosial mahu pun aspek kesihatan. Menurut World Health Organisation (WHO) lebih daripada 300 juta manusia seluruh dunia hidup dalam tekanan yang membawa kepada kesihatan mental dan ketidakupayaan. Sementara di Malaysia dianggarkan antara $8 \%$ ke $12 \%$ tekanan dialami oleh golongan wanita yang berpendapatan rendah, latar belakang sosio-ekonomi yang rendah dengan keadaan tahap kesihatan yang rendah (Jacob Achoi, 2017). Lebih daripada 2,000 orang setahun di negara ini melakukan percubaan untuk membunuh diri disebabkan tekanan dan mereka adalah dalam kalangan yang berumur antara 15 tahun ke 25 tahun dan antara 60 dan 80 tahun (Prof Dr T Maniam, pengerusi $29^{\text {th }}$ World Congress of the International Association for Suicide Prevention (IASP) and $21^{\text {st }}$ Malaysian Conference on Psychological Medicine 2017) (Jacob Achoi, 2017). Pelbagai masalah sosial dan kesihatan dalam anggota masyarakat tidak akan memberi kebaikan kepada kekuatan sistem dan struktur komuniti, masyarakat dan negara. Maka kajian perlulah dilakukan untuk mengetahui pengaruh status sosioekonomi rendah dan penyertaan sosial golongan belia masa kini.

\section{RUJUKAN}

Arieff, S. R. \& Wardah, M. (2006). Membentuk Jati Diri Remaja. Bentong: PTS Professional Publishing Sdn. Bhd.

Bradley, R. H. \& Corwyn, R. F. (2002). Socioeconomic Status and Child Development. Annual Review of Psychology, 53(3), 371-399.

Brenner, M. H. (2009). Explaining aggregate health status (mortality). Insights to the possible impact of the economic crisis. Report to the European Commission.

Dasar Pembangunan Belia Negara (1997). Diakses pada 24 Mac, 2015 daripada http://www.kbs.gov.my/dokumen2011/belia/Dasar\%20Pembangunan\%20Belia\%20Negara.pf

Dolly P. C. (2016). Isu di Sebalik Ponteng dan Keciciran Pelajar Sekolah dalam Researching Society and Social Relations in Sarawak. UNIMAS Publisher: UNIMAS, Kota Samarahan.

EACEA (Eurydice and Policy Support Unit (P9) of the Education, Education, Audiovisual and 
Culture Executive Agency). European Commission (2013). Youth Social Exclusion and Lessons from Youth Work-Evidence from Literature and Survey.Diakses pada 18 Julai, 2016darip0adahttp://eacea.ec.europa.eu/youth/tools/documents/social_exclusion_and_youth_ work.pdf.

Faizah, Y. (2007). Youth employment and employability in Malaysia. Round table discussion on youth for nation building. Diambil pada 24 Mac, 2015 daripada http://www.ippbm.gov.my/v2/index.php?option=com_rubberdoc\&view=category\&id=32\&ite mid $=25 \&$ lang $=$ bm\&limitstart $=20$

Julianty, P. \& Ning, S. (2013). Hubungan antara Tingkat Pendidikan, Pengetahuan tentang Kesehatan Lingkungan, Perilaku Hidup Sehat dengan Status Kesehatan. Pusat Teknologi Intervensi Kesehatan Masyarakat, Badan Litbang Kesehatan, Kemenkes RI, JI. Percetakan Negara 29 Jakarta.

Jacob, A. (2017, 20 July). Depression main cause of suicide. The Borneo Post. p. 3.

Kementerian Belia dan Sukan (1997). Dasar Pembangunan Belia Kebangsaan Malaysia. Diambil pada $24 \mathrm{Mac}, 2015$ daripada http://www.unescap.org/ esid/hds/youth/youth_malaysia.pdf

Man O. L. (2013). The Relationship between Family Socioeconomic Status and Lifestyle among Youth in Hong Kong. Discovery - SS Student E-Journal, 2, 135-168.

Mannes, M., Roehlkepartain, E. C., \& Benson, P. L. (2005). Unleashing the Power of Community To Strengthen the Well-Being of Children, Youth and Families: An Asset-Building Approach. Child Welfare League of America, 84(2), 33-250.

Mohd Razali, H. \& Sarjit S. G. (2010). Penyertaan belia dalam program pembangunan komuniti di Felda Jerangau, Terengganu. Malaysian Journal of Youth Studies, 3, 257-275.

Noor A. M. N. (1998). Satu Kajian Kes Masalah Remaja Sekolah dan Kaitannya dengan Pencapaian Akademik. Universiti Putra Malaysia. Tidak diterbitkan.

Norhayati S. (1994). Persekitaran Fizikal, Penglibatan Ibu Bapa dan Pencapaian Akademik KanakKanak di Rumah Pangsa. Univeristi Putra Malaysia. Tidak diterbitkan.

Psacharopoulos, G. (2007). The Costs of School Failure. Analytical Report for the European Commission prepared by the European Expert Network on Economics of Education (EENEE).

Ronka, A., Kinnunen, U., \& Pulkkinen, L. 2000. The Accumulation of Problems of Social Functioning as a Long-term Process: Women and Men Compared. International Journal of Behavioral Development, 24(4), 442-450.

Rozumah B., Rumaya J., Asnarul A. S., Tan J., Amna Md. N., \& Mansor A. T. (2005). Predictors of conduct problems among school-going adolescents in West Malaysia. Malaysian Journal of Social Policy and Society, 2, 92-107

Scutella, R., Wilkins, R., \& Horn, M. (2009). Measuring poverty and social exclusion in Australia: a 
proposed multidimensional framework for identifying socio-economic disadvantage, University of Melbourne, Melbourne.

UNESCO. Diambil pada 24 Mac, 2015 daripada http://www.unesco.org/ new/en/social-and-humansciences/themes/youth/

World Health Organisation. Diakses pada 24 July, 2018 http://www.who.int/news-room/factsheets/detail/depression

Veenstra, R., Lindenberg, S., Oldehinkel, A. J., De Winter, A. F., \& Ormel, J. (2006). Temperament, Environment, and Antisocial Behavior in a Population Sample of Preadolescent Boys and Girls. International Journal of Behavioral Development, 30(5), 422-432.

Zmerli, S. (2002). Bonding and bridging social capital. A relevant concept for political participation? Paper presented at ECPR Joint Sessions, Workshop No. 7, Tu-rin 